\title{
Análise dos estudos de capacidade de carga turística para os recifes de Picãozinho, Seixas (João Pessoa-PB) e Areia Vermelha (Cabedelo-PB)
}

Analysis of tourist carrying capacity studies for reefs Picãozinho, Seixas (João Pessoa-PB) and Areia Vermelha (Cabedelo-PB)

Análisis de los estudios de capacidad de carga turística para los recifes de Picãozinho, Seixas (João Pessoa-PB) y Areia vermelha (Cabedelo-PB) http://dx.doi.org/10.18472/cvt.16n1.2016.1005

Rhayany Juvêncio Costa < rhay-any@hotmail.com >

Mestranda em Desenvolvimento e Meio Ambiente pela Universidade Federal da Paraíba (UFPB), João Pessoa, PB, Brasil.

George Emmanuel Cavalcanti de Miranda 〈mirandag@dse.ufpb.br >

Professor do Programa de Pós-Graduação em Desenvolvimento e Meio Ambiente da Universidade Federal da Paraíba (UFPB), João Pessoa, PB, Brasil.

CRONOLOGIA DO PROCESSO EDITORIAL

Recebimento do artigo: 31-dez-2014

Aceite: $24-\mathrm{fev}-2016$

FORMATO PARA CITAÇÃO DESTE ARTIGO

COSTA, R. J; MIRANDA, G. E. C de. Análise dos estudos de capacidade de carga turística para os recifes de Picãozinho, Seixas (João Pessoa-PB) e Areia Vermelha (Cabedelo-PB). Caderno Virtual de Turismo. Rio de Janeiro, v. 16, n. 1, p. 60-73, abr. 2016.

$$
\text { REALIZAÇÃO }
$$

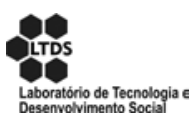

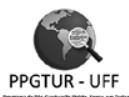

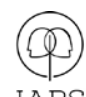

APOIO INSTITUCIONAL

COPPE
EDIÇÃO

EDITOR
PATROCÍNIO

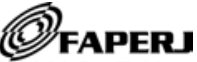




\section{RESUMO}

A crescente procura por atividades recreativas em ambientes naturais tem trazido à tona a necessidade do uso de ferramentas de planejamento turístico visando a realização de um turismo ordenado em que os danos causados aos locais de visitação sejam mínimos. A metodologia de capacidade de carga está relacionada à determinação do número máximo de pessoas em uma área sem que sejam provocados danos significativos ao ambiente visitado. Na Paraíba, os recifes costeiros de Picãozinho, Seixas e Areia Vermelha constituem formações recifais onde tem-se a realização de atividade turística durante o período da maré baixa quando piscinas naturais contendo uma diversidade de organismos marinhos tornam-se emersas. Os processos metodológicos envolveram levantamento bibliográfico dos estudos de capacidade de carga desenvolvidos para as três localidades durante os últimos dez anos. Neste estudo objetivamos rediscutir a eficiência de tais propostas por meio de uma análise crítica que destaque os aspectos ligados à metodologia para o desenvolvimento de um turismo sustentável. Os resultados apontaram que a determinação da capacidade de carga de uma área vem atrelada a uma grande subjetividade. Não é possível garantir que, por meio do número de usuários definido, os impactos de uma dada localidade sejam reduzidos ou eliminados. Ações de manejo em conjunto em um processo de planejamento contínuo são necessárias para um gerenciamento eficaz.

Palavras-chave: Capacidade de Carga Turística. Recifes Costeiros da Paraíba. Ferramentas de Planejamento Turístico.

\section{ABSTRACT}

The growing demand for recreational activities in natural environments has brought to light the need for tourist use planning tools aimed at the completion of a tourism ordained in which damage to visitation sites are minimal. Carrying capacity methodology is related to determining the maximum number of people in an area without to be caused significant damage caused to the environment visited. In Paraíba, coastal reef Picãozinho, Seixas and Areia Vermelha constitute reef formations where there is the realization of tourist activity during the period of low tide when natural pools containing a diversity of marine organisms become emerged. The methodological processes comprised bibliographic searching of the carrying capacity studies developed for three locations during the last ten years. In this study we aim to discurss again the efficiency of such proposals through a critical analysis that highlights the aspects of the methodology for the development of sustainable tourism. The results showed that the determination of the carrying capacity of an area is linked to a great subjectivity. There is no guarantee that through the number of users defined the impacts of a locality are reduced or eliminated. Actions complementary management in a continuous planning process are necessary for effective management.

Keywords: Tourist Carrying Capacity. Coastal reefs of Paraíba. Tools Tourism Planning.

\section{RESUMEN}

La creciente búsqueda de actividades recreativas en ambientes naturales ha traído consigo la necesidad del uso de herramientas de planificación turística con el objetivo de la realizar un turismo ordenado donde los impactos causados por esta actividad sean mínimos. La metodología de capacidad de carga está relacionada a la determinación del número máximo de personas en un área sin que sean provocados daños significativos al ambiente visitado. En Paraíba, los recifes costeros de Picãozinho, Seixas y Areia Vermelha constituyen formaciones recifales donde existe la realización de actividades turísticas durante el período de marea baja cuando las piscinas naturales exponen una diversidad de organismos marinos. Los procesos metodológicos involucran el levantamiento bibliográfico de los estudios de capacidad de carga desarrollados para las tres localidades durante los últimos diez años. En este estudio, buscamos debatir la eficiencia de tales propuestas a través de un análisis crítico que destaque los aspectos ligados a la metodología para el desarrollo de un turismo sostenible. Los resultados evidencian que la determinación de la capacidad de carga de un área está vinculada a una grande subjetividad, debido a que no es posible garantizar que a través de un número de usuarios 
definido los impactos de una localidad determinada sean reducidos o eliminados. Las acciones de manejo en conjunto en un proceso de planificación continuo son necesarias para una gestión eficaz.

Palabras clave: Capacidad de Carga Turística. Recifes Costeros de Paraíba. Herramientas de Planificación Turística.

\section{Introdução}

O turismo se encontra em um dos setores da economia com maior crescimento mundial. No Brasil, a participação do setor na economia já representa 3,7\% do Produto Interno Bruto (PIB) do País. Estima-se que em 2022 o turismo seja responsável por 3,63 milhões de empregos (BRASIL, 2015).

A necessidade de manter ou melhorar os recursos naturais ligados à potencialidade da atividade turística vem fazendo com que o setor se empenhe na busca de estratégias e políticas que visem o uso sustentável dos recursos naturais presentes nas destinações turísticas (ROCHA, 2011).

A preocupação com as questões ambientais globais vieram à tona a partir da década de 1980, nesta época, debates ambientalistas, reuniões em âmbito mundial se voltavam para a problemática ambiental global (NETO et al., 2011). Um dos primeiros esforços globais foi a introdução da noção de desenvolvimento sustentável apresentada inicialmente no Informe Brundtland, publicado como Nosso futuro comum, fruto do relatório da Comissão Mundial para o Meio Ambiente e o Desenvolvimento. De acordo com o informe, "O desenvolvimento sustentável é o desenvolvimento que satisfaz as necessidades do presente sem comprometer a capacidade das gerações futuras satisfazerem as suas próprias necessidades" (CMMAD, 1987, p. 24).

Dentro das discussões que envolvem o desenvolvimento sustentável, o turismo é apresentado como ferramenta de alcance de desenvolvimento econômico e de proteção dos recursos naturais (LINDBERG et al., 1996).

O ecoturismo, de acordo com o documento Diretrizes para uma Política Nacional de Ecoturismo publicado pela Embratur em parceria com o Ministério do Meio Ambiente, é definido como “...um segmento da atividade turística que utiliza, de forma sustentável, o patrimônio natural e cultural, incentiva sua conservação e busca a formação de uma consciência ambientalista através da interpretação do ambiente, promovendo o bem-estar das populações" (BRASIL, 1994, p. 9).

A qualidade de um atrativo turístico é baseada na originalidade ambiental e na capacidade de promoção de bem-estar do ambiente. Esses aspectos fundamentam a necessidade de controle e monitoramento do aumento do fluxo de visitantes em todo o mundo, considerando o fato de que os ecossistemas vulneráveis são prejudicados quando seus limites de capacidade de carga são extrapolados (RUSCHMANN, 1997).

De acordo com Teixeira \& Oliveira (2015, p. 121) "A crescente demanda turística por recursos naturais decorre da expansão da procura por atividades junto à natureza e toda visitação a esses locais causa algum tipo de impacto. Para isso é importante adotar medidas de identificação e controle para assegurar o uso sustentável dos ambientes". Entre as metodologias de capacidade de suporte tem-se como principais: Capacidade de carga - CCREC (CIFUENTES, 1992) e Limites de mudanças aceitáveis - LAC (STANKEY et al., 1985). 
O turismo em ambientes recifais constitui uma das possibilidades de utilização desses ecossistemas, entre tantos outros. A necessidade de um turismo baseado em princípios da sustentabilidade tem motivado o desenvolvimento de propostas de metodologias de planejamento turístico direcionadas a esses ambientes. A prática de um turismo sustentável vem se apresentando como uma possibilidade de minimização de impactos antropogênicos diante do uso irracional desses ambientes, principalmente no que se refere à exploração sobre os recursos naturais (SEGAL et al., 2007).

Picãozinho, Seixas e Areia Vermelha constituem formações recifais que ocorrem no litoral costeiro do Estado da Paraíba e que foram objeto de estudo no desenvolvimento de três propostas de capacidade de carga turística no decorrer dos últimos dez anos, desenvolvidas respectivamente por Debeus (2008), Melo (2006) e Lourenço (2010). Todos se basearam na metodologia Cifuentes (1992) como instrumento de planejamento turístico e definiu os seguintes valores de visitas diárias para as três localidades: Picãozinho, 273 visitas/dia; Seixas, 124 visitas/dia; Parque Estadual Marinho de Areia Vermelha, 1.225 visitas/dia.

Considerando os estudos citados, uma rediscussão da capacidade de carga nesses ambientes torna-se necessária, principalmente no que se refere: 1) A dificuldade de se identificar os impactos provocados especificamente pela atividade turística sobre o meio biológico e sua relação com o estabelecimento da capacidade de carga; 2) A discrepância de valores de capacidade de carga definidos para os ambientes recifais em estudo. Além de dificuldades intrínsecas do próprio método tais como a abordagem insuficiente dos impactos indiretos (resíduos sólidos, efluentes industriais e urbanos provindos da costa, erosão costeira, sedimentação, pesca predatória, entre outros) e a falta de revisão temporal dos valores.

Além das justificativas acima, o caráter flexível dos estudos de CCREC desenvolvidos nos três recifes deixam clara a liberdade para que haja a realização de novas pesquisas levando em consideração a característica não estática e susceptível a mudanças dos ambientes recifais. Melo (2006) vai afirmar que a capacidade de carga é "ajustável e passível de ser modificada, ao longo do tempo, com o advento de dados referentes à biota local, aos parâmetros físicos e químicos e ao aumento do fluxo turístico-recreativo".

Neste estudo objetivamos reavaliar os estudos e propostas de capacidade de carga desenvolvidas para os recifes de Picãozinho, Seixas e Areia Vermelha, por meio de uma análise crítica destacando os aspectos ligados à metodologia para o desenvolvimento de um turismo sustentável.

\section{Métodos}

Este trabalho foi desenvolvido a partir de uma análise crítica dos estudos de capacidade de carga desenvolvidos nos recifes de Picãozinho, Seixas e Areia Vermelha e das metodologias para definir capacidade de suporte pela atividade turística.

Segundo Lima e Mioto (2007, p. 38) "a pesquisa bibliográfica implica em um conjunto ordenado de procedimentos de busca por soluções, atento ao objeto de estudo, e que, por isso, não pode ser aleatório". De acordo com os autores, em um primeiro momento tem-se a escolha e problematização do tema, seguido do levantamento da bibliografia e das informações contidas nas referências para posterior análise documental e síntese integradora que consiste no resultado final, com síntese, reflexão e visualização de soluções. 


\section{Metodologia de capacidade de carga}

O conceito de capacidade de carga é oriundo do manejo de pastagens, no qual definia-se o número máximo de animais que uma área podia suportar baseado na capacidade de reposição das gramíneas. A partir da reformulação do conceito de capacidade de carga animal surgiu a capacidade de carga turística (DELGADO, 2007). A metodologia se fundamenta na determinação de um número máximo de usuários que uma área de visitação pode suportar sem que impactos significativos sejam ocorrentes (STANKEY; MANNING, 1986).

Os estudos de capacidade de carga com base na metodologia definida por Cifuentes, utilizados nos estudos em tela, consideram três etapas, cada qual apresentando-se como capacidade corrigida da outra, isto é, reduzida ou mantida em relação a anterior (CIFUENTES, 1992). Abaixo uma breve definição das etapas:

- Determinação da Capacidade de Carga Física (CCF) - relacionada ao espaço total disponível para a visitação, a quantidade de espaço necessária para cada usuário e ao período de tempo;

- Determinação da Capacidade de Carga Real (CCR) - ligada ao emprego dos fatores de correções (considerando variáveis físicas, ambientais, ecológicas, sociais e de manejo) atrelado às características particulares de cada localidade junto ao valor de CCF definido na etapa anterior;

- Determinação da Capacidade de Carga Efetiva (CCE) - leva em consideração aspectos referentes à disponibilidade dos recursos humanos, da infraestrutura e dos equipamentos necessários para que a atividade de visitação aconteça, junto ao valor de CCR definido na etapa anterior.

A metodologia sofreu duras críticas, principalmente no que se refere ao foco da ferramenta em determinar no número ideal de pessoas que uma determinada área pode suportar em vez das condições aceitáveis de visitação e como alcançá-las (TAKAHASHI; CEGANA, 2005). Para Delgado (2007) não é possível por meio da determinação de número mágico representar o limite a partir do qual as alterações ocasionadas pelas atividades de visitação causem danos ao ambiente. O autor afirma que "Esse conflito de opiniões surge em função do fato de que os impactos provocados pela visitação não estão unicamente atrelados ao número de visitantes, mas também à forma de visitação, às atividades desenvolvidas e à capacidade de manejo do local, entre outros fatores".

A ideia de desenvolvimento sustentável no turismo envolve o reconhecimento dos impactos negativos que a atividade pode acarretar assim como as ações de manejo necessárias para minimizá-los/detê-los para que a sustentabilidade seja alcançada. A capacidade de carga tem sido apontada como possível ferramenta capaz de considerar tais problemas, no entanto, não se adapta diante das complexidades encontradas na atividade turística (LINDBERG et al., 1996).

\section{Áreas de desenvolvimento dos estudos de capacidade de carga no litoral da paraíba}

Os recifes de Picãozinho ( $07^{\circ} 06^{\prime} 15^{\prime \prime}$ S, $\left.34^{\circ} 48^{\prime} 45^{\prime \prime} \mathrm{W}\right)$, Seixas $\left(07^{\circ} 09^{\prime} 08^{\prime \prime}\right.$, $\left.34^{\circ} 47^{\prime} 14^{\prime \prime} \mathrm{W}\right)$ e o Parque Estadual Marinho de Areia Vermelha $\left(07^{\circ} 00^{\prime} 41,95^{\prime \prime}\right.$, $\left.034^{\circ} 48^{\prime} 58,02^{\prime \prime} \mathrm{O}\right)$ constituem formações recifais que, durante o período da maré baixa, exibem piscinas naturais contendo uma diversidade de organismos marinhos (MELO, 2006; BATISTA et al., 2009; LOURENÇO, 2010) (Figura 1). 

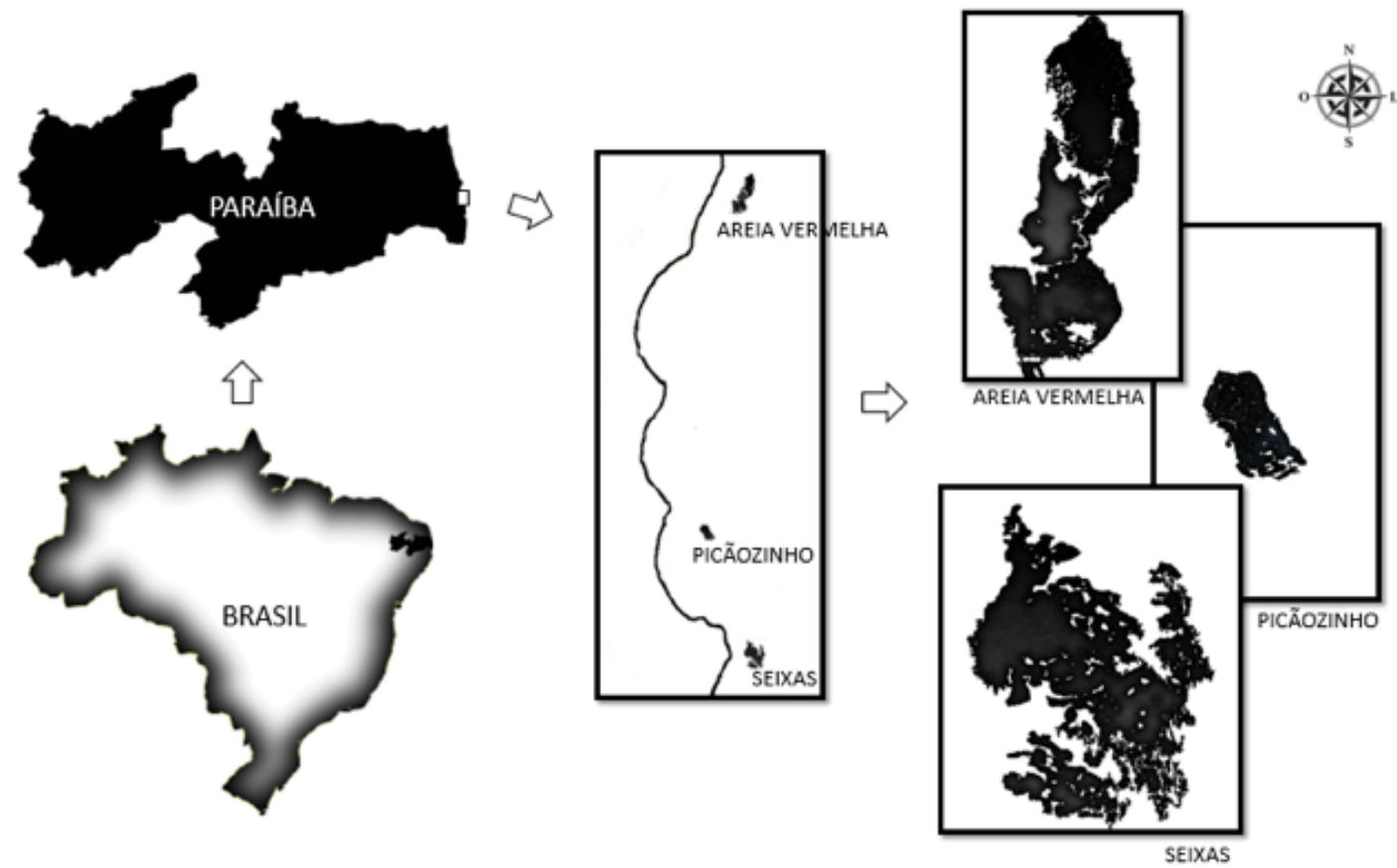

Figura 1. Localização dos recifes de Areia Vermelha, Picãozinho e Seixas Fonte: Elaborado pelo autor

Picãozinho (Figuras 1 e 2) localiza-se a cerca de $1.500 \mathrm{~m}$ da costa da praia de Tambaú em João Pessoa, Paraíba, e a realização de atividade turística sem o adequado planejamento ambiental e turístico acontece desde os últimos 15 anos (ILARRI et al., 2008; AMORIM; SASSI, 2009). O translado até a formação recifal dura em torno de 15 minutos com catamarãs bares que comportam em média de 40 a 100 usuários em busca de atividades de mergulho, e de fotografar a beleza natural (DEBEUS, 2008). Uma proposta de zoneamento baseada na diversidade de cnidários, facilidade de acesso e quantidade de piscinas e trilhas foi desenvolvida para a área objetivando ordenar as formas de uso, minimizar os conflitos existentes e reduzir os impactos ocasionados pela atividade turística (DEBEUS, 2012). A capacidade de carga efetiva definida por Debeus (2008) para a área teve aplicabilidade por meio do uso dos valores definidos no estudo do Termo de Ajustamento de Conduta - TAC (2010) pactuado entre os usuários.

O recife do Seixas (Figuras 1 e 2) dista aproximadamente $700 \mathrm{~m}$ da costa litorânea de João Pessoa, Paraíba, no Nordeste brasileiro e difere dos recifes de Picãozinho e Areia Vermelha por possuir um fluxo turístico menos intenso, no entanto, o desgaste desses dois ambientes principalmente no que se refere à sobrecarga turística-recreativa e a deterioração dos recifes pode vir a contribuir para o aumento do fluxo turístico neste (MELO, 2006). A área possui uma proposta de zoneamento levando em consideração os seguintes critérios: áreas de influência (impactos indiretos); aproveitamento dos locais utilizados atualmente; focos de biodiversidade; profundidade; rodízio de áreas (novas áreas com potencial turístico); ação das ondas e correntes e pescadores artesanais (MELO, 2008). Melo (2006) sugeriu uma capacidade de carga para a área, no entanto, o valor não foi empregado e a atividade é desenvolvida sem nenhuma norma de manejo que limite ou controle o número de visitantes.

Areia Vermelha (Figuras 1 e 2) apresenta-se como uma formação recifal com $3 \mathrm{~km}$ de extensão (Norte-Sul) localizada acerca de $1000 \mathrm{~m}$ da costa do município de Cabedelo, Paraíba (GONDIM et al., 2011), di- 
ferindo dos demais por exibir durante as marés baixas um banco de areia (LOURENÇO, 2010). Tornou-se Unidade de Conservação por meio do Decreto Estadual n. ${ }^{\circ} 21.263$ de 28 de agosto de 2000. Nos períodos de alta estação, tem-se na área a realização de um turismo massificado. Diversos impactos como pisoteio sobre o platô recifal, poluição por resíduos sólidos, alteração da beleza cênica pelo elevado número de embarcações, mesas e sombrinhas são observados no parque. Uma proposta de zoneamento e capacidade de carga foi desenvolvida por Lourenço (2010), porém, na prática os mesmos não são utilizados.
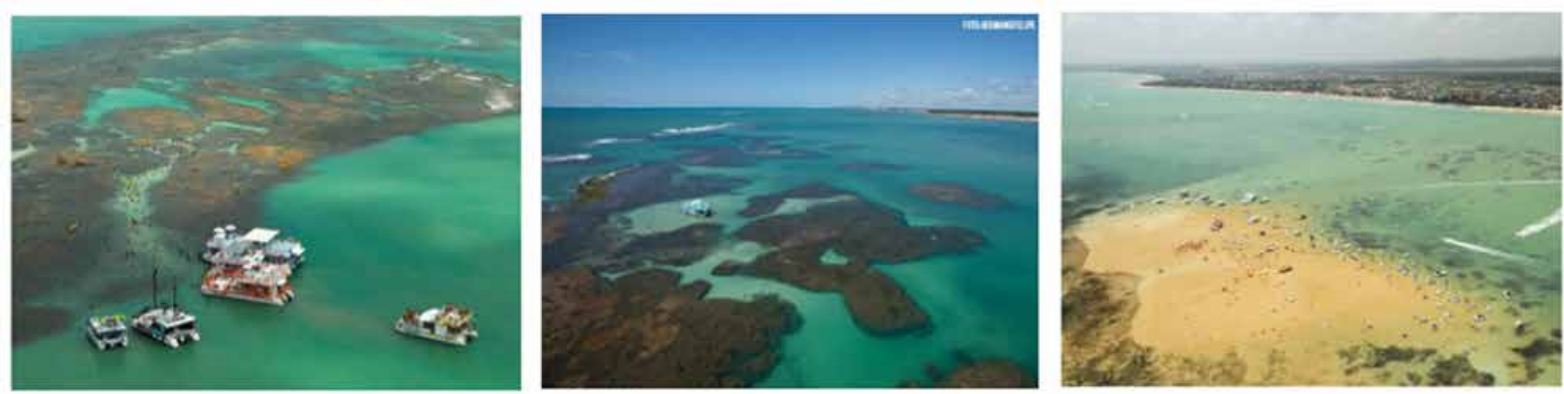

Figura 2. Fotografias de Picãozinho, Seixas e Areia Vermelha

Fonte: Luck receptivo; Renoturismo / Germano Felipe e PBTur / Cacio Murilo

\section{Resultados e discussões}

Os estudos de capacidade de carga nos ambientes recifais costeiros no Estado da Paraíba constituíram uma contribuição relevante ao ordenamento turístico, entretanto, aspectos limitantes ligados à metodologia de capacidade de carga podem vir a interferir nos resultados esperados no processo de planejamento turístico. A rediscussão e avaliação das propostas de capacidade de carga desenvolvidas até o momento nos recifes costeiros da Paraíba apresentam-se como essenciais para o desenvolvimento de um turismo sustentável.

O total de visitas diárias definidas por Melo (2006), Debeus (2008) e Lourenço (2010) para os três ambientes recifais e dados empregados na determinação da capacidade de carga podem ser conferidos nas tabelas abaixo:

Tabela 1. Número de visitas diárias para os recifes de Picãozinho, Seixas e Areia Vermelha

\begin{tabular}{|c|c|c|c|}
\hline & Picãozinho & Seixas & Areia Vermelha \\
\hline $\begin{array}{c}\text { Capacidade de Carga } \\
\text { Física (CCF) }\end{array}$ & 10.529 visitas/dia & 714 visitas/dia & 37.182 visitas/dia \\
\hline $\begin{array}{l}\text { Capacidade de Carga } \\
\text { Real (CCR) }\end{array}$ & 273 visitas/dia & 124 visitas/dia & 1.225 visitas/dia \\
\hline $\begin{array}{l}\text { Capacidade de Carga } \\
\text { Efetiva (CCE) }\end{array}$ & 242 visitas/dia & 26 visitas/dia & $-\star$ \\
\hline
\end{tabular}

*A Capacidade de Carga Efetiva não foi calculada no PEMAV pelo autor (LOURENÇO), justificando ser de difícil mensuração.

Fonte: Melo (2006); Debeus (2008); Lourenço (2010). 
Tabela 2. Dados empregados na determinação da capacidade de carga turística nos recifes de Picãozinho, Seixas e Areia Vermelha

\begin{tabular}{|c|c|c|c|}
\hline & Picãozinho & Seixas & Areia Vermelha \\
\hline Superfície total/visitante & $\begin{array}{l}21058,07 \mathrm{~m} 2 / 3 \mathrm{~m} 2- \\
\text { Padrão WTO }\end{array}$ & $\begin{array}{l}1070,7 \text { m2/3 m2 } \\
\text { - Padrão WTO }\end{array}$ & $\begin{array}{l}\text { Zona de Uso Turístico- } \\
\text { Recreativo } \\
105977,39 \mathrm{~m} 2 / 20 \mathrm{~m} 2 \\
\text { Zona de Uso Tradicional e } \\
\text { Recreativo } \\
33546,42 \mathrm{~m} 2 / 20 \mathrm{~m} 2 \\
\text { Zona Primitiva } \\
18304,62 \mathrm{~m} 2 / 3 \mathrm{~m} 2\end{array}$ \\
\hline $\begin{array}{c}\text { Tempo total aberto/ } \\
\text { visitação }\end{array}$ & 3 horas $/ 2$ horas & 3 horas $/ 1,5$ hora & $\begin{array}{l}\text { Zona de Uso Turístico- } \\
\text { Recreativo } \\
4 \text { horas/ } 2 \text { horas } \\
\text { Zona de Uso Tradicional e } \\
\text { Recreativo } \\
4 \text { horas/3 horas } \\
\text { Zona Primitiva } \\
4 \text { horas } / 1 \text { hora }\end{array}$ \\
\hline Fatores limitantes & $\begin{array}{l}\text { - Estação chuvosa } \\
\text { - Nível da maré (limite } \\
0,5 \text { ) } \\
\text { - Área de ancoragem } \\
\text { - Pisoteio } \\
\text { - Fator social (grupos) }\end{array}$ & $\begin{array}{l}\text { - Estação chuvosa } \\
\text { - Nível da maré } \\
\text { (limite } 0,5) \\
\text { - Área de } \\
\text { ancoragem }\end{array}$ & $\begin{array}{l}\text { Zona de Uso Turístico- } \\
\text { Recreativo } \\
\text { - Estação chuvosa } \\
\text { - Nível da maré (limite 0,5) } \\
\text { - Pisoteio } \\
\text { - Acessibilidade } \\
\text { - Fundeio de embarcações } \\
\text { Zona de Uso Tradicional e } \\
\text { Recreativo } \\
\text { - Estação chuvosa } \\
\text { - Nível da maré (limite 0,5) } \\
\text { Zona Primitiva } \\
\text { - Estação chuvosa } \\
\text { - Nível da maré (limite 0,5) } \\
\text { - Pisoteio } \\
\text { - Fator social }\end{array}$ \\
\hline
\end{tabular}

Fonte: Melo (2006); Debeus (2008); Lourenço (2010).

Com base nos dados extraídos dos estudos acima podemos destacar os seguintes elementos para discussão: 


\section{Discrepância de valores}

Picãozinho, Seixas e Areia Vermelha representam formações recifais onde é possível identificar algumas similaridades principalmente em relação ao tipo de ambiente e formação recifal, e ao público-alvo: praticantes de snorkeling e não de scuba, ao clima, ao nível da maré e à composição bêntica (DEBEUS, 2008; VUELTA, 2000; GONDIM et al., 2011). Entretanto, os valores estabelecidos para cada ambiente (Tabela 1) divergem consideravelmente.

É possível que essa discrepância observada mais fortemente entre Picãozinho e Seixas, dada a sua similaridade, seja explicada pela área total utilizada na base dos cálculos da primeira etapa (CCF), enquanto Melo (2006) estimou para uma região restrita do recife, efetivamente utilizável pelos turistas (uma única piscina natural), Debeus (2008) extrapolou para todo o ambiente recifal de Picãozinho incluindo áreas não utilizadas na atividade turística originando essa distorção.

Ainda que seja considerado que foram utilizados diferentes fatores de correção (Tabela 2) para se determinar a capacidade de carga turística dos referidos recifes, a diferença no número de visitas diárias é flagrante, principalmente entre Seixas e Picãozinho, citada anteriormente, onde, de acordo com Debeus (2008) o primeiro pode ser considerado como uma extensão das barreiras que compreendem o segundo, reforçando a semelhança das duas localidades. Por outro lado, a presença de um banco de areia exposto durante as marés baixas em Areia Vermelha pode justificar o número significativamente maior de visitantes/dia alcançado (LOURENÇO, 2010).

Vale ressaltar que caso os recursos necessários para a visitação (capacidade adequada) sejam melhorados/alcançados em detrimento dos recursos existentes (capacidade instalada) o número de usuários pode aumentar tendo como limite o valor definido na segunda etapa, na Capacidade de Carga Real. O valor estabelecido pelo TAC (2010) para Picãozinho, por exemplo, pode vir a aumentar em face de melhoras nos equipamentos, infraestrutura e recursos humanos. Fato que pode reforçar ainda mais tal discrepância de valores.

\section{Obstáculos no processo de identificação dos impactos da atividade turística}

Outra limitação atrelada aos estudos de capacidade de carga desenvolvidos em Picãozinho, Seixas e Areia Vermelha se refere à dificuldade em identificar os impactos provocados especificamente pela atividade turística sobre o meio biológico e sua relação com o estabelecimento da capacidade de carga. Para Stankey et al. (1985), os estudos de CCREC não indicam a existência de relação direta entre número de visitantes e quantidade de impactos gerados, e estes estão muito mais ligados ao comportamento dos visitantes do que ao número de pessoas.

Por meio da metodologia de capacidade de carga não é possível comprovar que os impactos causados aos três ambientes em estudo são oriundos especificamente da atividade turística. É preciso considerar que fatores externos como ação das ondas e dos ventos, por exemplo, realizam interferência direta no ecossistema recifal. Separar impacto turístico de impacto externo constitui um desafio e este dificilmente poderá ser superado por meio da utilização da metodologia de capacidade de carga. Uma alternativa seria o emprego em conjunto de ferramentas que incluam o uso de indicadores capazes de refletir o mais próximo possível as reais condições ambientais de determinada área, em um processo de monitoramento contínuo. 


\section{Distanciamento dos impactos indiretos}

A não abordagem aos impactos indiretos (resíduos sólidos, efluentes industriais e urbanos provindos da costa, erosão costeira, sedimentação, pesca predatória, etc.) vai representar outra fragilidade dos estudos de capacidade de carga desenvolvidos nos três recifes em questão. Segundo Melo (2006), os estudos de capacidade de carga vão envolver em seus conteúdos questões relativas aos impactos ambientais físicos, ou seja, os impactos diretos. Para o autor "Aí é que reside o problema em relação à validade e utilidade desses estudos, pois, dependendo do local, os impactos indiretos podem ter um peso maior do que os impactos diretos nos recifes" (MELO, 2006. p. 412).

Impactos indiretos, a exemplo da pesca de arrasto realizada externamente aos ambientes recifais, podem ocasionar alterações em toda a dinâmica do ecossistema recifal, chegando a gerar impactos maiores que os próprios danos diretos. O lançamento de efluentes urbanos provindos da costa, como consequência do processo de urbanização costeira, gerando alterações na qualidade da água, também exemplifica outra forma de impacto, que indiretamente e a longo prazo é capaz de desencadear degradação ambiental.

\section{Subjetividade atrelada à metodologia}

A metodologia falha ao ligar os impactos da visitação simplesmente ao quantitativo de usuários, aspectos subjetivos, a exemplo do comportamento do visitante, podem apresentar um peso bem maior. Um pequeno grupo de visitantes não informados/instruídos são capazes de gerar danos mais expressivos ao ambiente natural que uma grande quantidade de visitantes orientados e com conduta consciente. (DELGADO, 2007).

Os estudos de capacidade de carga, em sua maioria, não consideram o fator biológico, a maior parte dos fatores limitantes utilizados nas três pesquisas em questão está ligada a aspectos econômicos e sociais. Como reduzir os impactos de visitação se utilizando de variáveis que não apresentam ligação direta com as alterações ocasionadas pelas atividades de visitação? Outro aspecto ligado ao emprego dos fatores de correções e que reflete a subjetividade que norteia a metodologia se refere ao quantitativo. É possível que Debeus (2008) tenha tentado reduzir a quantidade elevada de usuários definida na primeira etapa em Picãozinho, que considera a área utilizada para a recreação, aplicando uma maior quantidade de fatores de correção na segunda etapa, na determinação da Capacidade de Carga Real.

Em face das limitações atreladas à metodologia de capacidade de carga autores têm apoiado o uso de ferramentas alternativas, a exemplo da metodologia de limites de mudanças aceitáveis - LAC (STANKEY et al., 1985). A ideia básica da ferramenta consiste na determinação do quanto de alterações o ambiente pode suportar, para em seguida pensar em ações de manejo que alcancem/mantenham as condições adequadas. O estabelecimento do quanto o ambiente suporta de mudanças, do limite de mudanças aceitável, é baseado no uso de indicadores ambientais capazes de refletir as condições do meio em que estão inseridos. Caso os limites inaceitáveis sejam atingidos, medidas de monitoramento de impacto e de controle de visitação com mudanças na administração das visitas podem ser tomadas.

A ferramenta LAC teve sua primeira implementação no complexo selvagem Bob Marshall, no Estado de Montana, nos Estados Unidos, em uma grande área natural protegida com cerca de 682.000 hectares contendo uma série de cadeias de montanhas, caracterizada pela realização de atividade recreativa em níveis relativamente baixos, com cerca de $2.500 \mathrm{~km}$ de trilhas e mais de 1.500 campings. Nos Estados Unidos o LAC tem sido atrelado a programas de participação popular, com resultados bem-sucedidos no melhoramento do processo de gestão das áreas protegidas (MCCOOL, 1996). 
Em um estudo envolvendo ambientes recifais, no Mu Koh Chang National Marine Park, na Tailândia, Roman et al. (2007) agregou fatores ecológicos e sociais em duas estratégias de planejamento turístico: zoneamento e LAC. Para definição dos limites aceitáveis de mudança para cada zona foram levados em consideração aspectos biofísicos, baseados em índices de mortalidade e vulnerabilidade dos corais, e aspectos sociais, baseados na percepção e nível de satisfação dos visitantes relacionados às atividades de snorkeling. O limite de mudança aceitável para o indicador biofísico foi de 0,35 para o índice de mortalidade do coral. Para o indicador social foi definido como menos de 30 mergulhadores por zona como aceitável.

Quando empregada, a metodologia de capacidade de carga não deve ser trabalhada de maneira isolada, a ferramenta deve ser entendida como uma estratégia de manejo complementar a outras ações. $\mathrm{Na}$ literatura encontramos a metodologia de Cifuentes (1992) com aplicação em ambiente recifal em San Andrés Isla, na Colômbia (GALLO et al., 2001); para determinação da capacidade de carga recreativa foram considerados os seguintes fatores de correção: Fator social, considerando o tamanho dos grupos por guia, duração da visitação e distância entre os grupos; Fator de fragilidade; Fator de danos por toque, Fator de ancoragem, Fator de evacuação e Fator de acessibilidade do vento. A capacidade de carga proposta foi de 29 mergulhos diários. O autor ressalta que a determinação da capacidade de carga representa uma forma de avaliação de intensidade de uso e não se caracteriza como principal estratégia de manejo.

Os autores das propostas de capacidade de carga para Picãozinho, Seixas e Areia Vermelha reconhecem que a determinação do número de usuários não deve ser um valor estático, que há necessidade de uma reavaliação periódica do valor estabelecido considerando que os ambientes recifais e a atividade turística são dinâmicos e susceptíveis a mudanças ao longo do tempo. No entanto, observa-se que na prática não há um processo contínuo de monitoramento capaz de rever a capacidade de carga definida, caso exemplificado por Picãozinho, cuja incorporação da proposta de capacidade de carga definida pelo TAC (2010) permanece fixa sem estudos de reavaliações. Lime e Stankey (1971) afirmam que o conceito de capacidade é multidimensional e dinâmico, para eles, a capacidade de carga recreativa não consiste simplesmente na determinação de um valor absoluto e fixo, pois o manejo recreativo leva em consideração um complexo conjunto de condições.

\section{Considerações finais}

A determinação da capacidade de carga de uma área vem atrelada a uma grande subjetividade; a redução da subjetividade pode ser atingida a partir da definição de indicadores biológicos sensíveis. Não é possível garantir que, por meio do número de usuários definido, os impactos de uma dada localidade sejam reduzidos ou eliminados. Quando empregada, a capacidade de carga não deve ser uma ferramenta utilizada de forma isolada, ações de manejo em conjunto em um processo de planejamento contínuo são necessárias para um gerenciamento eficaz.

A presente análise crítica não consiste em julgar a metodologia de planejamento turístico em questão como correta ou ineficaz, os estudos avaliados foram desenvolvidos dentro de critérios técnicos científicos adequados, entretanto, a subjetividade e a ausência de monitoramento e atualização por parte do setor público, gestor dessas áreas, tornam esses números valores que devem ser utilizados com restrições.

Tanto a ferramenta de capacidade de carga como a de limites de mudanças aceitáveis vão apresentar aspectos positivos e negativos. A escolha da metodologia a ser empregada em uma dada área deve se 
adequar aos objetivos da pesquisa. Se o objetivo, por exemplo, é a definição de um número de usuários, o emprego da capacidade de carga se apresenta como uma opção, aspecto que a LAC não poderia suprir satisfatoriamente; se por outro lado o objetivo é monitorar, fazer ajustes em um contexto onde já haja uma metodologia em vigor, o uso do limite de mudanças aceitáveis, sugerindo ações de manejo de controle como redução/aumento do número de usuários, redução/aumento no tempo de visitação, baseado no uso de indicadores, torna-se a metodologia mais adequada.

\section{Referências}

AMORIM, T. P. L.; SASSI, R. Microssimbiontes associados à Millepora alcicornis (Linnaeus, 1758) (Cnidaria, Hydrozoa) dos recifes costeiros de Picãozinho, João Pessoa-PB, 2009.

BATISTA, J. B; LEONEL, R. M. V; COSTA, M. A. J. Características populacionais de Microphrys bicornutus (Brachyura, Mithracidae) no fital Halimeda opuntia (Chlorophyta, Halimedaceae), em área recifal submetida à visitação humana, em João Pessoa, Paraíba. Iheringia Série Zoologia, v. 99, p. 44-52, 2009.

BRASIL, EMBRATUR. Diretrizes para uma Política Nacional de Ecoturismo. Brasília. EMBRATUR/IBAMA, 1994.

BRASIL. Ministério do Turismo. Plano Nacional de Turismo 2013-2016. Brasília, DF, 2015. Disponível em: 〈http://www.turismo.gov.br/images/pdf/plano_nacional_2013.pdf). Acesso em: 4 dez. 2015.

CIFUENTES, M. Determinación de capacidad de carga turística en áreas protegidas. Bib. Orton IICA/ CATIE, 1992.

COMISSÃO MUNDIAL SOBRE MEIO AMBIENTE E DESENVOLVIMENTO - CMMAD. Nosso Futuro Comum. Rio de Janeiro: FGV, 1991.

DEBEUS, G; CRISPIM, M. C. 0 turismo nas piscinas naturais de Picãozinho, João Pessoa, PB Percepções, Conflitos e Alternativas. Revista de Estudos Ambientais, v. 10, n. 1, p. 21-32, 2008.

DEBEUS, G. Turismo Sustentável como Alternativa de Desenvolvimento e Conservação do Meio Ambiente em Picãozinho - Município de João Pessoa - PB. Dissertação (Mestrado em Desenvolvimento e Meio Ambiente - PRODEMA) Universidade Federal da Paraíba, João Pessoa, 2008. Disponível em: 〈http://www.prpg.ufpb.br/prodema/novosite/smartgc/uploads/arquivos/guilherme_debeus.pdf〉 Acesso em: 10 jun. 2015

DEBEUS, G; LIMA, E. R. V; CRISPIM, M. C. Proposta de Zoneamento para o Ambiente Recifal de Picãozinho, João Pessoa-PB. Revista Gaia Scientia, 2012.

DELGADO, M. Análise da metodologia criada por Miguel Cifuentes referente à capacidade de carga turística. Revista Turismo em Análise, v. 18, n. 1, p. 73-93, 2007.

FERREIRA, B. P; MAIDA, M. Monitoramento dos recifes de coral do Brasil: situação atual e perspectivas. MMA/SBF, 2006. Disponivel em: 〈http://www.mma.gov.br/estruturas/chm/_arquivos/18_ introducaobr.pdf $>$. Acesso em: 16 out. 2013.

GALLO, F.; MARTINEZ, A.; RIOS, J. I. Capacidad de carga de visitantes em áreas de buceo de San Andrés Isla (Colombia). Universidad Tecnológica de Pereira, 2001. 
GONDIM, A. I. et al. Macrofauna bêntica do Parque Estadual Marinho de Areia Vermelha, Cabedelo, Paraíba, Brasil; Benthic macrofauna from Areia Vermelha Marine State Park, Cabedelo, Paraíba, Brazil. Biota neotrop. (On-line, Ed. port.), v. 11, n. 2, p. 75-86, 2011.

GRAEFE, A. R.; KUSS, F. R.; VASKE, J. J. Visitor impact management: the planning framework. Washington, DC: National Parks and Conservation Association, (S.n.t). 1990.

ILARRI, M. I. et al. Effects of tourist visitation and supplementary feeding on fish assemblage composition on a tropical reef in the Southwestern Atlantic. Neotropical Ichthyology, v. 6, n. 4, p. 651-656, 2008.

LIMA, T. C. S; MIOTO, R. C. T. Procedimentos metodológicos na construção do conhecimento científico: a pesquisa bibliográfica. Revista Katálysis, v. 10, n. 1, p. 37-45, 2007.

LIME, D. W; STANKEY, G. H. Carrying capacity: maintaining outdoor recreation quality. Recreation Symposium Proceedings, v. 12, n. 14. Northeastern Forest Experiment Station, Forest Service, US Department of Agriculture Upper Darby, Pennsylvania, 1971.

LINDBERG, K; MCCOOL, S; STANKEY, G. Rethinking carrying capacity. Annals of tourism research, v. 24, n. 2, p. 461-465, 19967.

LOURENÇO, L. de J. S. Proposta de Zoneamento e Capacidade de Carga para o Parque Estadual Marinho de Areia Vermelha. Dissertação de Mestrado (Mestrado em Desenvolvimento e Meio Ambiente - PRODEMA). UFPB. João Pessoa. 2010. Disponível em: 〈http://tede.biblioteca.ufpb.br/ handle/tede/4517\#preview-linko>. Acesso em: 15 ago. 2015

MCCOOL, S. F. Limits of acceptable change: a framework for managing national protected areas: experiences from the United States. In: workshop on impact management in marine parks, sponsored by Maritime Institute of Malaysia. 1996.

MELO, R. S. et al. Estimativa da capacidade de carga recreativa dos ambientes recifais da Praia do Seixas (Paraíba, Brasil). Turismo-Visão e Ação, v. 8, n. 3, p. 411-422, 2006.

MELO, R. S. et al. Planejamento turístico e zoneamento ambiental: um estudo de caso nos ambientes recifais das praias do Seixas, Penha e Arraial (Paraíba, Brasil). Caderno Virtual de Turismo, v. 8, n. 2, 2008.

NETO, J. M; KRÜGER, C. M; DZIEDZIC, M. Análise de indicadores ambientais no reservatório do Passaúna. Eng Sanit Ambient, v. 14, n. 2, p. 205-214, 2009.

ROCHA, J. M. Desenvolvimento e sustentabilidade do turismo: preceitos da teoria da capacidade de carga turística. Rosa dos Ventos - Turismo e Hospitalidade, v. 3, n. 3, 2011.

ROMAN, G. S. J; DEARDEN, P; ROLLINS, R. Application of zoning and "limits of acceptable change" to manage snorkeling tourism. Environmental Management, v. 39, n. 6, p. 819-830, 2007.

RUSCHMANN, D. V. M. Turismo e planejamento sustentável: a proteção do meio ambiente. Papirus Editora, 1997.

SEGAL, B. et al. Turismo sustentável em ambientes recifais. Projeto Coral Vivo. 2007.

STANKEY, G. H. et al. The limits of acceptable change (LAC) system for wilderness planning. Ogden, UT: Gen. Techn. Rep. INT. USLJA Forest Service, n. 176, p. 37, 1985.

STANKEY, G; MANNING, R. Carrying capacity of recreation settings. A Literature Review: The President's Commission on Americans Outdoors. Washington: US Government Printing Office, p. 47-57, 1986. 
TAKAHASHI, L. Y; CEGANA, A. C. Como monitorar o impacto dos visitantes utilizando o sistema LAC Limite Aceitável de Câmbio. Revista Turismo em Análise, v. 16, n. 2, p. 206-222, 2005.

TEIXEIRA, P. R; OLIVEIRA, L. T. O Método de Cifuentes e a Avaliação da Capacidade de Carga na Trilha na 'Serrinha'. São João da Baliza, Roraima. Revista Rosa dos Ventos - Turismo e Hospitalidade, v. 7, n. 1, p. 120-132, jan-mar, 2015. Disponível em: 〈http://dx.doi.org/10.18226/21789061.v7iss1p120〉. Acesso em: 10 dez. 2015.

VUELTA, C. B. A ictiofauna e a presença do turismo no recife de Picãozinho, Paraíba, Brasil. Dissertação de Mestrado. Universidade Federal da Paraíba, João Pessoa (PB), Brasil, 2000. 